\title{
Early prescribed fire in the Serra da Canastra National Park as a strategy to contain large fires within the Integrated Fire Management Plan
}

\author{
Fernando Augusto Tambelini Tizianel ${ }^{1}$, Sávio Freire Bruno ${ }^{2}$, Bianca Thais Zorzi Tizianel ${ }^{*}$
}

\footnotetext{
${ }^{1}$ Serra da Canastra National Park- Instituto Chico Mendes de Conservação da Biodiversidade (ICMBio);

${ }^{2}$ Universidade Federal Fluminense (UFF)

*E-mail para contato: bianca.tizianel@icmbio.gov.br
}

\begin{abstract}
The Serra da Canastra National Park has 200,000 hectares, with extensive continuous native wilderness areas, and historically is hit by large fires that mainly damage forest formations and wildlife. The accumulation of fuel due to the adoption of the zero-fire policy favored the occurrence of fires that, several times, reached more than 25,000 hectares per event. With the objective of creating mosaics of areas with different ages of burning, which can function as fire barriers and as protection of conservation targets (defined in the Integrated Fire Management Plan of the Protected Area), prescribed burns were made between January 16 and April 5, 2019 (rainy season) in the area of the Chapadão da Canastra. The choice of areas to be managed considered the area reached by fire in the previous year, the Fuel Accumulation Map produced from the Spectral Angle Mapper (SAM) of the Landsat Satellite 8, and the areas with the highest fire recurrence. The areas affected by lightning fires during the months of December/2018 and January/2019 (2,100 hectares) were also taken into account. All prescribed fires were preceded by a specific Burn Plan and completion of the Follow-up Form. Prescription parameters adopted, based on previous local experiences, were: temperature minimum 18 $\circ$ / maximum $28^{\circ}$; relative humidity minimum 60\% / maximum 100\%; wind speed minimum - / maximum $10 \mathrm{~km} / \mathrm{h}$. A total of 5,464 hectares were managed. The controlled burns were performed at different times of the day, always within the prescribed parameters. Fire intensity (visual and sensory analysis) varied according to the area's fuel accumulation, which also influenced on the occurrence of natural extinction or need for combat. The activity has been accompanied by research from the Fluminense Federal University. As a result, the burnings fragmented the Chapadão da Canastra, hoping to facilitate the fighting and to prevent the spread of fires. In addition, firebreaks will be made. The prescribed fire had social support from the region, where the fire is historically used as a farming tool. It is necessary to increase scientific monitoring of the effects of prescribed fire for biodiversity conservation.
\end{abstract}

Keywords: prescribed fire, integrated fire management 